\title{
Preliminary Localization of a Gene for Autosomal Dominant Hypoparathyroidism to Chromosome 3q13
}

\author{
DAVID N. FINEGOLD, MARLENE M. ARMITAGE, MAE GALIANI, TARA C. MATISE, \\ M. R. PANDIAN, YVETTE M. PERRY, RANJAN DEKA, AND ROBERT E. FERRELL \\ Department of Pediatrics, School of Medicine, University of Pittsburgh, Pittsburgh, \\ Pennsylvania 15261 [D.N.F.]; Department of Human Genetics, Graduate School of Public \\ Health, University of Pittsburgh, Pittsbungh, Pennsylvania 15261 [M.M.A., T.C.M., Y.M.P., \\ R.D., R.E.F.]; Department of Pediatrics, School of Medicine, Yale University, New Haven, \\ Connecticut 06504 [M.G.]; and Nichols Institute, San Juan Capistrano, \\ California 92690 [M.R.P.]
}

\section{ABSTRACT}

A large family in which hypoparathyroidism was observed to segregate as an autosomal dominant trait in three generations was identified. Mutation in the PTH gene was excluded by linkage and single-stranded conformational analysis. The hypocalcemic phenotype in this family was mapped by linkage analysis using short, tandem-repeat polymorphisms to the region of chromosome $3 q 13$. A maximum lod score of 2.71 at $\Theta$ $=0.0$ was observed with marker D3S1303. Positive lod scores were observed at $\Theta=0.0$ with markers flanking D3S1303. Multipoint linkage analysis gave a lod score of 2.71 for the region flanking D3S1303. Simulation using the computer program SLINK showed that a lod score of 2.71 at $\Theta=0.0$ was the maximum lod score possible given the pedigree structure. The simulation also showed that given the structure of the pedigree the probability of observing a lod score of 2.71 at $\Theta=$ 0.0 by chance was 1 in 1000 . The data presented above provide important preliminary evidence supporting linkage to chromosome $3 q 13$. This region contains a $\mathrm{Ca}^{2+}$-sensing receptor gene that is proposed as a key signal transduction element for changes in extracellular $\mathrm{Ca}^{2+}$ concentrations in mechanisms of regulation of PTH secretion from parathyroid cells. The mutation in this family may activate the $\mathrm{Ca}^{2+}$-sensing receptor suppressing PTH secretion and lowering the "set point" for serum calcium levels. (Pediatr Res 36: 414-417, 1994)
Idiopathic hypoparathyroidism is an unusual endocrine deficiency characterized by decreased levels of PTH without an obvious etiology such as surgical trauma. The clinical presentation is variable, with symptoms ranging from mild parasthesias to tetany and convulsions. Hypocalcemia and hyperphosphatemia are commonly seen and vary in severity. Familial clustering of hypoparathyroidism has been described with transmission patterns consistent with autosomal dominant, autosomal recessive, and $\mathrm{X}$-linked inheritance. The mechanism of at least some of the recessively inherited forms has been characterized as mutations in the sequence of the PTH gene (1-3). On the other hand, hypoparathyroidism with an

Received for rapid publication May 11, 1994; accepted June 9, 1994.

Correspondence: David N. Finegold, M.D., Associate Professor of Pediatrics, Division of Pediatric Endocrinology, Children's Hospital of Pittsburgh, 3705 Fifth Ave. at DeSoto St., Pittsburgh, PA 15213.

Supported in part by a grant from the W. M. Keck Foundation for Advanced Training in Computational Biology at the University of Pittsburgh, Carnegie Mellon University, and the Pittsburgh Supercomputing Center, and in part by Pittsburgh Supercomputing Center Grant 1-P41-RR06009 from the NIH National Center for Research Resources (T.C.M.). autosomal dominant pattern of transmission has been reported to be unlinked to the PTH locus $(4,5)$ and is unlikely to represent a simple mutation within the PTH gene sequence. We had the opportunity to study three generations of a family with inherited hypoparathyroidism, demonstrating an autosomal dominant transmission pattern. In this family, hypocalcemia was rarely clinically manifested, hypoparathyroidism was unlinked to the PTH locus, and no abnormality in the PTH coding sequence was detected by single-stranded DNA conformational analysis (data not shown). In light of these results, we reasoned that autosomal dominant hypoparathyroidism must be explained by a mutation other than in the PTH gene. Using highly informative microsatellite markers, we have preliminary evidence that the locus responsible for the hypoparathyroid phenotype in this family maps to chromosome $3 q 13$.

\section{METHODS}

Genotyping. Genomic DNA was isolated from peripheral blood. Amplification primers were synthesized using 
sequence information from the Genome Database and end labeled by standard procedures. Genomic DNA was polymerase chain reaction amplified with $0.144 \mu \mathrm{M}$ labeled primers and $0.8 \mu \mathrm{M}$ unlabeled primers by standard protocol. Amplification was conducted for 30 cycles at $94^{\circ} \mathrm{C}$ for $1 \mathrm{~min}, 52^{\circ} \mathrm{C}$ for $1 \mathrm{~min}$, and $72^{\circ} \mathrm{C}$ for $1 \mathrm{~min}$, with a final one-cycle extension at $72^{\circ} \mathrm{C}$ for $5 \mathrm{~min}$. Amplified products were electrophoresed on standard denaturing $7 \%$ acrylamide $/ 35 \%$ formamide DNA sequencing gels.

Linkage analyses. We tested for linkage in this family between hypoparathyroidism and the following 11 microsatellite loci on chromosome 3q: D3S1302, D3S1278, D3S1310, D3S1303, D3S1267, D3S1269, D3S1273, D3S1290, D3S1292 (6), RHO, and ACPP (7). The LINKAGE programs MLINK, LODSCORE, and LINKMAP (8) were used for two-point and multipoint linkage analyses. The disease was assumed to be autosomal dominant with complete penetrance and a disease gene frequency of 0.001 . For the two-point analyses, allele frequencies reported in the Human Genome Data Base (9) were used where possible; otherwise, frequencies were estimated from unrelated founders. Because no recombinants were detected between D3S1290 and D3S1292 in our family and in eight CEPH families (6), D3S1290 was used to represent this locus, inasmuch as it was more informative in this family. Markers D3S1310 and D3S1278 could not be ordered unequivocally in CEPH families. We used D3S1278 in multipoint analysis because it was the most informative in our family.

Marker order for the multipoint linkage analysis was determined by using CRI-MAP (10) to refine the map of this region as reported in Matise et al. (11). The map order and intermarker recombination fractions were D3S1302-0.04-D3S1278-0.07-D3S1303-0.03-D3S12670.01-D3S1269-0.07-D3S1273-0.02-D3S1290-0.001-RHO0.06-ACPP. Braverman's recoding algorithm (12) was used to reduce the number of alleles for some markers. We repeated the two-point linkage analysis with the recoded markers to validate the recoded alleles and obtained lod scores equal to or slightly lower than those estimated with the original alleles. We performed several overlapping multipoint analyses, computing the lod score at each map position within each interval. Lod scores were plotted for the innermost map interval of each multipoint analysis, with the exception of the terminal map intervals.

We used the SLINK and MSIM simulation and analysis program $(13,14)$ to estimate the likelihood of obtaining significant two-point lod scores in this pedigree. We generated 2000 replicates of this pedigree using the observed phenotypes and simulating a marker with the same allele frequencies as D3S1303. The allele frequencies of D3S1303 were used because this marker had the highest two-point lod score. Simulations were performed under both a completely linked model $(\Theta=0.0)$ and a completely unlinked model $(\Theta=0.5)$.

\section{RESULTS}

Family. A 2-mo-old boy was referred to the endocrine clinic of the Children's Hospital of Pittsburgh with a history of hypocalcemia at $1 \mathrm{~d}$ of age and a strong maternal family history of hypocalcemia. Because of the family history, the referring physician had determined the infant's serum calcium level shortly after birth and noted a reduced level of $1.75 \mathrm{mM}$. The infant showed no signs of neuromuscular irritability, tetany, or seizures, but was started on oral calcium supplements. Repeat $\mathrm{Ca}^{2+}$ determinations continued to be slightly low at $2.07-2.12 \mathrm{mM}$. On presentation to the endocrine clinic, a remarkable family history was elicited. The child's mother had a history of hypocalcemia since early childhood, with hypocalcemic seizures at age 3-4 y and again at 13-14 y during intercurrent illness. She was currently not on any medications but remembered receiving medications to treat hypocalcemia in the past. The pedigree (Fig. 1) based on a family history of hypocalcemia demonstrates an autosomal dominant pattern of inheritance. On physical examination, the proband appeared to be a healthy infant without dysmorphic features. Height was $56 \mathrm{~cm}$ (25th percentile). Weight was $5.64 \mathrm{~kg}$ (75th percentile). Head circumference was $38 \mathrm{~cm}$ (25th percentile). The remainder of the examination was unremarkable, with the exception of an aortic ejection murmur that was later evaluated and felt to be caused by a bicuspid aortic valve. In view of the family history, physical examination, and laboratory results, calcium supplementation was discontinued without exacerbation of symptoms or further decrease in serum $\mathrm{Ca}^{2+}$ concentrations.

The results of the biochemical analysis from family members demonstrated a separation in serum calcium

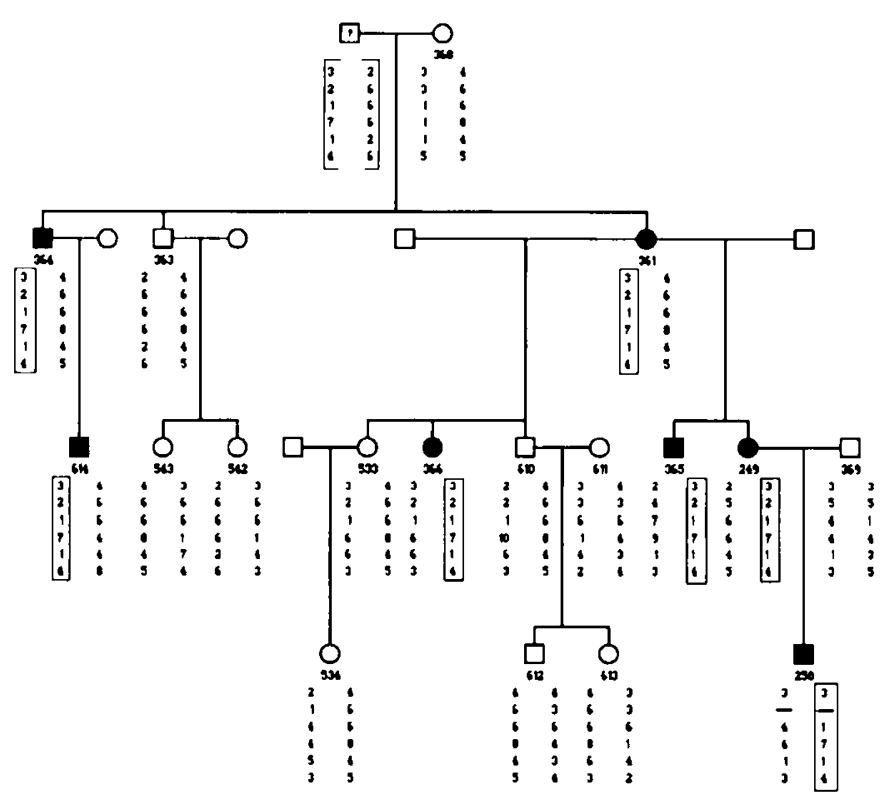

Figure 1. Segregation of hypoparathyroidism and six linked marker genotypes in three generations. Numbers arranged vertically refer to genotypes for the markers D3S1302, D3S1278, D3S1310, D3S1303, D3S1267, and D3S1269. Inferred genotypes are given in brackets. 
between affected and unaffected individuals. Serum total $\mathrm{Ca}^{2+}$ levels were low in affected members [mean $\pm \mathrm{SD}$, $1.85 \pm 0.05 \mathrm{mM}(n=5)$ versus $2.42 \pm 0.09 \mathrm{mM}(n=8)$; normal range, $2.20-2.69 \mathrm{mM}$ ]. Ionized $\mathrm{Ca}^{2+}$ levels were also low $(0.89 \pm 0.01 \mathrm{mM}$ versus $1.17 \pm 0.07 \mathrm{mM}$; normal range, 1.15-1.35 $\mathrm{mM}$ ). Phosphorus levels were high, and the PTH levels were low or undetectable. Only the maternal grandmother was receiving a vitamin D preparation, without effect on her hypocalcemia. No family member was disabled by symptoms of hypocalcemia. The biochemical findings confirm the autosomal dominant pattern of transmission of hypoparathyroidism in the family.

Linkage analysis. Recent evidence has supported the existence of a $\mathrm{Ca}^{2+}$-sensing receptor as an element of the mechanisms regulating PTH secretion from parathyroid cells (15). The human $\mathrm{Ca}^{2+}$-sensing receptor gene has recently been mapped to chromosome 3 . We tested our family for linkage between hypoparathyroidism and a series of short, tandem-repeat polymorphisms spanning the approximate location of the $\mathrm{Ca}^{2+}$-sensing receptor locus. The results of the linkage analysis are presented in Table 1. A maximum lod score of 2.71 (odds favoring linkage $>500: 1)$ at $\Theta=0.0$ for marker D3S1303 was observed. Positive lod scores were observed at $\Theta=0.0$ with markers D3S1302, D3S1278, D3S1267, D3S1269, and RHO, which flank D3S1303 and the locus for hypoparathyroidism. The observed pattern of lod scores is consistent with the known order of these markers on chromosome 3q13.

Multipoint lod score analysis using nine markers gave a lod score of 2.71 for the region flanking the marker D3S1303. Multipoint linkage analysis using all informative markers gives a 1-lod confidence interval for assignment of a gene for autosomal dominant hypoparathyroidism to a 47-centimorgan region of human chromosome 3q13 flanking the marker D3S1303. To evaluate the linkage results, we used SLINK $(13,14)$ (see Methods) to simulate the segregation of marker alleles in this pedigree under two assumptions: first, that the marker locus was linked to the phenotype with no recombination; and second, that the marker was unlinked to the

Table 1. LOD scores for linkage between familial hypoparathyroidism and genetic markers from human chromosome $3 q$

\begin{tabular}{lcrrrrrr}
\hline \multirow{2}{*}{$\begin{array}{c}\text { Test } \\
\text { locus }\end{array}$} & \multicolumn{1}{c}{ LOD scores at $\Theta=$} \\
\cline { 2 - 8 } D3S1302 & 2.04 & 2.00 & 1.86 & 1.68 & 1.27 & 0.82 & 0.36 \\
D3S1278 & 2.08 & 2.04 & 1.90 & 1.70 & 1.30 & 0.86 & 0.42 \\
D3S1310 & -1.13 & -0.95 & -0.66 & -0.51 & -0.33 & -0.22 & -0.13 \\
D3S1303 & 2.71 & 2.67 & 2.49 & 2.25 & 1.75 & 1.19 & 0.60 \\
D3S1267 & 0.94 & 0.91 & 0.78 & 0.63 & 0.40 & 0.22 & 0.07 \\
D3S1269 & 2.41 & 2.36 & 2.19 & 1.96 & 1.47 & 0.97 & 0.46 \\
D3S1273 & $-\infty$ & 0.67 & 1.21 & 1.30 & 1.14 & 0.83 & 0.43 \\
D3S1290 & $-\infty$ & 0.67 & 1.21 & 1.30 & 1.14 & 0.83 & 0.43 \\
D3S1292 & $-\infty$ & 0.37 & 0.93 & 1.04 & 0.94 & 0.68 & 0.35 \\
RHO & 0.59 & 0.58 & 0.55 & 0.50 & 0.39 & 0.28 & 0.15 \\
ACPP & $-\infty$ & 0.05 & 0.63 & 0.77 & 0.72 & 0.52 & 0.26 \\
\hline
\end{tabular}

phenotype. In the linked case, the maximum observed lod score was 2.71 at $\Theta=0.0$. This corresponds to the observed two-point lod score for locus D3S1303. Thus, the linkage results are consistent with complete linkage between autosomal dominant hypoparathyroidism and marker D3S1303. Among 2000 replicates of the unlinked model, a lod score of 2.5-2.7 was observed only twice. This suggests that the observed lod score of 2.71 between autosomal dominant hypoparathyroidism and marker D3S1303 is not due to chance $(p \leq 0.001)$.

\section{DISCUSSION}

Linkage to multiple microsatellite markers supports the preliminary assignment of a gene responsible for hypoparathyroidism to chromosome $3 q 13$. In this family, the lod score for linkage was 2.71 , and multipoint analysis did not increase the lod score because marker D3S1303 was completely informative. Using the general simulation program for linkage analysis SLINK to simulate segregation of an unlinked marker, the likelihood of the observed lod score seen in our family appearing by chance was 1 in 1000. Similarly, assuming linkage, the predicted maximum lod score for this family was 2.71 , as observed for marker D3S1303 and haplotypes for markers D3S1302, D3S1278, D3S1310, D3S1303, D3S1267, and D3S1269. The cosegregation of the hypoparathyroidism phenotype with six highly informative microsatellite markers, the observation of the maximum possible lod score in this family for the marker D3S1303, and the low probability of observing a lod score of 2.71 in this family by chance alone $(p \leq 0.001)$ all support the assignment of a gene causing hypoparathyroidism to human chromosome $3 q 13$.

Recent work has expanded our knowledge of the regulation of extracellular $\mathrm{Ca}^{2+}$ and PTH. Brown (15) has reviewed the evidence addressing the mechanisms that control PTH secretion from parathyroid cells. Acute regulation of PTH secretion appears to be modulated by a $\mathrm{Ca}^{2+}$-sensing receptor coupled via a $\mathrm{G}$ protein-mediated mechanism of activation of phospholipase $\mathrm{C}$, affecting levels of inositol triphosphate. Such a receptor has been cloned and characterized from bovine parathyroid cells and expressed in Xenopus oocytes (16). The human receptor has been mapped to chromosome $3 \mathrm{q}$ by Pollak et al. (17). The $\mathrm{Ca}^{2+}$-sensing receptor gene has the motif of the seven membrane-spanning domain $\mathrm{G}$ protein-coupled receptors. Mutations in the human $\mathrm{Ca}^{2+}$-sensing receptor gene have been linked to neonatal severe hyperparathyroidism and familial hypocalciuric hypercalcemia (17, 18). These mutations result in a loss of function of the $\mathrm{Ca}^{2+}$-sensing receptor determined in a Xenopus expression assay.

The $\mathrm{Ca}^{2+}$-sensing receptor gene is a likely candidate for the phenotype seen in our family. The hypocalcemia is mild, and none of the family members have required hormonal or calcium supplementation beyond childhood. This would be consistent with the single dose of the gene 
inferred from the linkage analysis. Depression in PTH secretion would predict a gain of function mutation, forcing the receptor to the "on" state. The mild hypocalcemic phenotype segregates in this family as an autosomal dominant trait. However, in a manner similar to the observations of loss of function mutations seen in neonatal severe hyperparathyroidism $(17,18)$, a double dose of gain of function mutation might be expected to cause severe hypocalcemia requiring vitamin $\mathrm{D}$ and $\mathrm{Ca}^{2+}$ supplementation. Previous reports of inherited hypoparathyroidism have been explained by mutations in the PTH gene or were ascribed to "anatomic" malformations of the parathyroid glands. We believe at least a subset of familial dominant hypoparathyroidism may be explained by mutations in the PCAR1 gene.

Khosla et al. (19) and Marx et al. (20) have suggested that familial hypocalciuric hypercalcemia and neonatal severe hyperparathyroidism represent "set-point" abnormalities in the maintenance of extracellular $\mathrm{Ca}^{2+}$ concentration. The potential for heterogeneity in "set-point" for serum $\mathrm{Ca}^{2+}$ concentration raises the possibility that mildly affected probands may have other unsuspected hypocalcemic relatives. This would be similar to the initial reports in familial hypocalciuric hypercalcemia of individuals in the pedigrees with unsuspected hypercalcemia. Families of individuals diagnosed with hypoparathyroidism and absent parathyroid antibodies should be screened for mild hypocalcemia to avoid unnecessary treatment with calcium and vitamin D supplementation and identify the potential risk for hypocalcemic seizures during childhood illnesses.

\section{REFERENCES}

1. Arnold A, Horst SA, Gardella TJ, Baba H, Levine MA, Kronenberg HM 1990 Mutation of the signal peptide-encoding region of the preproparathyroid hormone gene in familial isolated hypoparathyroidism. J Clin Invest 86:1084 1087

2. Parkinson DB, Thakker RV 1992 A donor splice site mutation in the parathyroid hormone gene is associated with autosomal recessive hypoparathyroidism. Nature Genet 1:149-152
3. Miric A, Levine MA 1992 Analysis of the preproPTH gene by denaturing gradient gel electrophoresis in familial isolated hypoparathyroidism. J Clin Endocrinol Metab 74:509-516

4. Schmidtke J, Kruse K, Pape B. Sippell G 1986 Exclusion of close linkage between the parathyroid hormone gene and a mutant gene locus causing idiopathic hypoparathyroidism. J Med Genet 23:217-219

5. Parkinson DB, Shaw NJ, Himsworth RL, Thakker RV 1993 Parathyroid hormone gene analysis in autosomal hypoparathyroidism using an intragenic tetranucleotide (AAAT) (n) polymorphism. Hum Genet 91:281-284

6. Weissenbach J, Gyapay G, Dib C, Vignal A, Morissette J, Millasseau P, Vaysseix G, Lathrop M 1992 A second-generation linkage map of the human genome. Nature 359:794-801

7. NIH/CEPH Collaborative Mapping Group 1992 A comprehensive genetic linkage map of the human genome. Science 258:67-86

8. Lathrop GM, Lalouel JM, Julier C, Ott J 1984 Strategies for multilocus linkage analysis in humans. Proc Natl Acad Sci USA 81:3443-3446

9. Cuttichia A, Fasman K, Kingsbury D, Robbins R, Pearson P 1993 The GDB(TM) Human Genome Data Base Anno 1993. Nucleic Acids Res 21:3003-3006

10. Lander ES, Green $P 1987$ Construction of multi-locus genetic linkage maps in humans. Proc Natl Acad Sci USA 84:2363-2367

11. Matise T, Perlin M, Chakravarti A 1994 Automated construction of genetic linkage maps using an expert system (MultiMap): a human genome linkage map. Nature Genet 6:384-390

12. Braverman MS $1985 \mathrm{An}$ algorithm to improve the computational efficiency of genetic linkage analysis. Comp Biomed Res $8: 24-36$

13. Ott J 1989 Computer-simulation methods in human linkage analysis. Proc Natl Acad Sci USA 86:4175-4178

14. Weeks DE, Ott J, Lathrop GM 1990 SLINK: a general simulation program for linkage analysis. Am J Hum Genet 47:A204(abstr)

15. Brown EM 1991 Extracellular $\mathrm{Ca}^{2+}$ sensing, regulation of parathyroid cell function, and role of $\mathrm{Ca}^{2+}$ and other ions as extracellular (first) messengers. Physiol Rev 71:371-411

16. Brown EM, Gamba G, Riccardi D, Lombardi M, Butters R, Kifor O, Sun A, Hediger MA, Lytton J, Hebert SC 1993 Cloning and characterization of an extracellular $\mathrm{Ca}^{2+}$-sensing receptor from bovine parathyroid. Nature 366:575-580

17. Pollak MR, Brown EM, Chou YW, Herbert SC, Marx J, Steinmann B, Levi T, Seidman CE, Seidman JG 1993 Mutations in the human $\mathrm{Ca}^{2+}$-sensing receptor gene cause familial hypocalciuric hypocalcemia and neonatal severe hyperparathyroidism. Cell 75:1297-1303

18. Pollak MR, Chou YW, Marx SJ, Steinmann B, Cole DEC, Brandi ML, Papapoulous SE, Menko FH, Hendy GN, Brown EM, Seidman CE, Seidman JG 1994 Familial hypocalciuric hypercalcemia and neonatal severe hyperparathyroidism. Effects of gene dosage on phenotype. J Clin Invest 93:1108-1112

19. Khosla S, Ebeling PR, Firek AF, Burritt MM, Kao PC, Heath H 1993 Calcium infusion suggests a "set-point" abnormality of parathyroid gland function in familial benign hypercalcemia and more complex disturbances in primary hypoparathyroidism. J Clin Endocrinol Metab 76:715-720

20. Marx SJ, Lasker RD, Brown EM, Fitzpatrick LA, Sweezey NB, Goldbloom RB, Gillis DA, Cole DEC 1986 Secretory dysfunction in parathyroid cells from a neonate with severe primary hyperparathyroidism. J Clin Endocrinol Metab 62:445-449 